\title{
Biofuel sustainability: relationships between the directive 2009/28/EC and scientific research
}

\author{
Luca Spreafico ${ }^{1, *}$, Massimo Peri ${ }^{2}$ \\ ${ }^{1,2}$ Department of Agricultural, Food and Environmental Economics \\ Università degli Studi di Milano, Milan, Italy \\ * Corresponding author. Tel: +39 50316469, Fax: +39 50316486, E-mail: luca.spreafico3@studenti.unimi.it
}

\begin{abstract}
With the aim to reinforce the sustainability of biofuel production the EU directive 2009/28/EC has recently introduced a set of criteria aiming to reduce environmental effects of uncontrolled biofuel production. The criteria introduced by the directive define a procedure to compute the Green House Gases (GHG) emission of biofuel production based on the Life Cycle Analysis (LCA) approach. Nevertheless, although this approach is quite consolidated in some production systems, it represents a novelty in the biofuel sector. Using the Strengths, Weaknesses, Opportunities and Threats (SWOT) analysis in this paper it is compared the approach introduced by the directive with the main results emerged from a s election of papers, on the same subject, published in international journals in the last five years. The main results show as the new approach and the calculation method adopted could be a positive guideline for a better assessment of GHG emission at European level. However, some aspect could improve the efficiency of the new directive. Indirect land use change, functional unit and the involvement of other environmental impacts are some of the aspects that should be considered in order to refine the directive calculation method. Moreover, the paper highlights how it is fundamental to establish a right trade-off between LCA application and bureaucratic constraints for economic agents operating in biofuel production chain.
\end{abstract}

Keywords: Biofuel sustainability, Life Cycle Analysis, Directive 2009/28/EC

\section{Introduction}

Biofuels are considered one of the best alternatives to mineral oil derivatives in the transport sector, so their production and consumption are highly supported by the political framework, especially in Europe and in the United States. Although biofuels cover a small part of total energy requirement, the increasing demand could make doubtful their real sustainability, especially considering that feedstock production takes place in different countries around the world. In this regard there is a broad debate from which emerge several opinions: sceptical positions on the usefulness of biofuels (e.g.: Koonin, 2006; Odling, 2007; Righelato and Spracklen, 2007); judgements and criticisms (e.g.: Fargione et al., 2008; Melillo et al., 2009); encouraging considerations on $\mathrm{f}$ uture prevision related to the develop of the secondgeneration biofuels (e.g. Tilman et al. 2006; Fargione et al., 2008). The debate still remain open and the opinions on the effectiveness of a biofuel policy are not always in agreement (e.g. Kennedy, 2007; Robertson et al., 2008; Fargione, et al., 2008). From a conceptual point of view reasoning on biofuel sustainability pass through the definition of what basis utilize to discriminate which of them are sustainable and then identify the sustainable policy framework for biofuel development. In this regard it could be useful to decompose the question into two elements: the first, technical, seeks to understand whether biofuels are sustainable products, while the second, institutional, it is dedicated to understand whether the implemented policy framework to promote biofuels is sustainable.

These two aspects support each other: it is politically correct to promote the biofuels use only if they prove to be technically sustainable (in particular if the goal of the political action is precisely the sustainability), on the other hand, not having the absolute certainty that such products are sustainable, or that the production methods are sustainable, the policy action can 
orient economic operators to those supply chains able to demonstrate their sustainability by using rules, certifications system or other effective evaluation methods.

In line with the existing implemented policy framework for biofuel development and with the aim to reinforce the sustainability of EU biofuel production the directive 2009/28/EC has recently introduced a set of criteria aiming to reduce environmental effects of uncontrolled biofuel productions incorporating technical patterns into institutional framework. The criteria introduced by the directive define a procedure to compute the Green House Gases (GHG) emission of biofuel production based on the Life Cycle Analysis (LCA) cradle-to-grave approach. Nevertheless, although LCA approach is quite consolidated in some production systems, it represents a novelty in the biofuel sector. Using the Strengths, Weaknesses, Opportunities and Threats (SWOT) analysis in this paper it is compared the approach introduced by the directive with the main results emerged from a selection of papers, on the same subject, published within international journals during the last five years.

\section{The SWOT analysis applied to the LCA approach of the directive 2009/28/EC}

From a theoretical point of view the SWOT analysis is an evaluation methodology that assess the possibility for a subject to achieve a goal highlighting strengths and weaknesses of the subject and the opportunities and threats that can occur from his setting, in respect to the goal. In order to analyse possible benefits, problems, opportunities and limits that can occur in the application of the LCA in the biofuel sector as regulated form the recent directive 2009/28/EC on the promotion of the use of energy from renewable sources, in this paper strengths and weaknesses are pointed out by comparing the directive with the institutional framework, while opportunities and threats are highlighted examining the technical aspect emerged from a literature review concerning the LCA methodology applied to biofuel sector.

\subsection{Strengths and Weaknesses}

Strengths and weaknesses of the application of the directive are deduced from the analysis of the relationship between the content of the directive and the political objectives that European Union aim to achieve through a sustainable development of biofuels sector. From a conceptual point of view to identify strengths and weaknesses the paper analyse the three major objectives of the EU biofuel policy (energy security, climate change mitigation and rural development) in respect to the principal sector involved by the application of the directive such as biofuel sector, energy sector, agricultural and food sector, environment and rural development. Within this contest strengths and weaknesses are presented considering that what in the directive can be helpful to reach these objectives has been considered strengths, while problems about biofuels development that the directive can not solve has been treated as weaknesses.

\subsubsection{Strengths}

Before declining the different aspects that could be classified as strengths it is important to highlight some general concepts having a positive impact on the institutional framework. Before the adoption of the directive the EU political framework in support of biofuel developments were only related to production incentives both on the supply and demand side. Among the different policies implemented in the EU to stimulate biofuel supply, we recall the directive 2003/96/EC on energy taxation, the energy crop premium and the non-food set-aside payment. While on the demand side, we recall the directive 2003/30/EC on the promotion of biofuel use, which fixed a share of biofuel blends equal to $2 \%$ of the overall consumption of gasoline and diesel in transport for the end of 2005, rising to 5.75\% in 2010. Moreover, the 
directive here examined (2009/28/EC), has increased the European biofuel target to $10 \%$ by 2020. This political framework has had a great impact on production: from 2005, the first biofuel target year of the directive 2003/30/EC, to 2009, the EU-25 biodiesel production rose to $184 \%$. In the same period biodiesel production capacity increased from 4.2 to 20.9 million tons, the equivalent of an increment of $395 \%$ (EBB, 2010).

Considering the uncontrolled development of biofuel production, the adoption of the directive with sustainable constrain for biofuel production and use can be viewed as the only way for the prosecution of the European biofuel policy. In this regard, one of the more significant strengths of the directive is that it is highly innovative and in line with the European political action, that is largely based on the enhancement of sustainability goals. Moreover the new framework imposed by the directive forces Member States to monitoring the environmental, economical and political problems related to biofuels production and consumption, providing new basis for consciously decisions.

In respect to the biofuel sector the new target fixed by the directive, equal to $10 \%$ of renewable energy in transport sector by 2020 , is set up in a more clear framework able to demonstrate and communicate the real sustainability of biofuel products. This new scenario could stimulate institutional investors that could be attracted by the ethic aspect of sustainable biofuel and in the same time also new investors can look at biofuel sector with a growing interest in relation to the reduced risk related to a m ore controlled supply chains, as a consequence of the application of the LCA approach.

Also the agricultural and food sector is indirectly involved by the directive, indeed it allows a double counting of energy produced by waste, residues and lingo-cellulosic biomass. Trough this mechanism the second generation of biofuels are promoted and then, the so criticized conflict between food and non food use of feedstock, should be attenuated.

From the environmental point of view two related aspects can be considered as strengths. First, the directive fixes a minimum level of GHG reduction, so the environmental benefit can be assured, second the calculation method for the GHG emission is fixed and equal for all EU Member States, reducing technical disagreement in emissions assessment and consequently market asymmetry and trade distortions.

\subsubsection{Weaknesses}

As for the strengths patterns, also for the weaknesses can be formulated some general considerations related to the adoption of the directive. If the innovative character of the directive is analysed as a strengths pattern, from a conceptual point of view it could be also viewed as a limitation, indeed it is possible that it can be incomplete and inexact.

Monitoring of environmental, economic and political aspect imposed to Member State is not sufficient to control these problems, in the directive there are not specific interventions able to manage indirect land use change, fluctuation in commodities prices and food insecurity. However, it is admitted that these problems are very complex and their management required more knowledge. Through the National Action Plan the directive encourages the processing sector and the biofuel consumption, but does not highlight any specific intervention in support of farmers. The sustainable standard introduced with the adoption of the directive could be viewed as a constrain in the commercial relation, European imports restriction imposed on non sustainable biomass and biofuels could stimulate international trade partners to introduce non tariff barriers on other relevant products for European community. Another general 
weaknesses is related to the methodology adopted for the calculation of the GHG reduction, indeed the directive suggests two different approaches, analytic and concise, that could produce different results.

In respect to the implication related to the biofuel sector the introduction of the mass balance system, as a method for the traceability of the products, does not appear completely clear. This unsettled contest opens the interpretation and application of the directive liable to a lobby activity from processing and trader agents reducing the efficiency of all the system.

With reference to agricultural and food sector it is possible to underline that no specific and direct interventions are considered to reduce food no food conflict, so the promotion of sustainable biofuels could not be enough to reduce this conflict. Moreover within the directive there are not specific actions devoted to promote biofuels supply chains in rural areas. Finally, with regard to energy sector, although the contribute of biofuel development to energy security is, at the moment, in absolute value limited, their development do not contribute to energy security. Indeed the feedstock necessary for biofuels production in the next future will continue to be imported from extra EU country, making null the contribute of biofuel sector to the energy independency goal, simply the question shifts from fossil fuel to food commodity. Indeed, the Commission itself expects an increasing flow of imports of biomass for biofuel use. Moreover, these latter questions appear in contrast with the recent publication of the proposal reform of the Common Agricultural Policy for the period past 2013, where one of the three main objectives is directed to revaluate the European food security.

\subsection{Opportunities and Threats}

In this article the opportunities and threats related to the adoption of the directive are investigated in respect to the technical pattern, looking up weather biofuels are sustainable products in respect to their GHG emission within the contest of LCA approach. In order to highlight the most widespread problems the paper has compared the methodology proposed by the directive with the main results, on the same topics, emerged from a literature review. The paper has considered fourteen articles relative to the LCA application in biofuels sector published on international journals during the period 2004 to 2010.

The articles considered span from general reports where authors compare several LCA with the aim to underline the origin of the variability in the results obtained to very critical articles that explain conceptual mistakes in LCA structure and proposing new methods to assess biofuels sustainability.

In the following it is itemized the main criticisms of LCA application to biofuel sector emerged from literature review:

- definition of the system boundaries of LCA analysis; system boundaries should be consistent with the goal of analysis, because outputs are greatly affected by the numbers of steps considered in supply chain examined (Feng et al., 2008; Gnansounou et al., 2009; Quirin et al., 2004; Rowe, 2009; Singh et al., 2009).

- definition of the reference systems; to obtain reliable results of GHG reduction, it is relevant to have clearly defined reference systems as regards fossil fuels, alternative uses of biomass, uses of co-products substitutes (Cherubini et al., 2009; Gnansounou et al., 2009; Quirin et al., 2004).

- choice of functional unit; functional unit should be consistent with the system boundaries considered. The same biofuel can appear sustainable using one functional 
unit and not sustainable using another (Cherubini et al., 2009; Gnanosunou et al., 2009; Quirin et al., 2004; Singh et al., 2009).

- choice of input considered; when the inputs considered are different, biofuel sustainability could appear different within the same system boundaries (Rowe, 2009).

- data quality and representativeness; data used in LCA could be out-of-date or little representative, a particular phenomenon could be difficult to measure, so data could not be reliable. Moreover the data used could be significant only for local condition considered and then not replicable in different context (Cherubini et al., 2009; Chiaramonti and Recchia, 2010; Larson, 2006; Menichette and Otto, 2008; Quirin et al., 2004; Rowe, 2009).

- assessment of another environmental impacts; $\mathrm{CO}_{2}$ emissions are always assessed, but other GHG are also important, besides other possible impacts, like acidification or eutrophication, could occur during biofuels production (Delucchi, 2004; Larson, 2006; Menichette and Otto, 2008; Quirin et al., 2004).

- efficiency of energy conversion; it is important to consider the energy efficiency of engines and conversion plants. Indeed, with high engine efficiency emissions are lower (Delucchi, 2004; Larson, 2006; Menichette and Otto 2008; Rowe, 2009).

- consideration of fuels/biofuels mixtures; technical features of mixtures affects emission levels (Croezen and Kampman, 2009; Gnansounou et al., 2009)

- effects of agricultural residues removal; the removal of agricultural residues for producing biofuels could affects the level of $\mathrm{CO}_{2}$ emissions, so this effect should be assessed and considered (Cherubini et al., 2009).

- choice of allocation method; different allocation methods of GHG emissions between biofuels and co-products cause different results (Chiaramonti and Recchia, 2010; Gnansounou et al., 2009, Larson, 2006; Luo et al., 2009, Menichette and Otto 2008; Quirin et al., 2004; Rowe, 2009; Singh et al., 2009; Wang et al., 2010).

- consideration of direct land use change; this phenomenon is highly relevant because it can cause $\mathrm{CO}_{2}$ emissions or savings, so LCAs should consider it (Cherubini et al., 2009; Delucchi, 2004, Gnansounou et al., 2009; Larson, 2006; Menichette and Otto, 2008).

- consideration of indirect land use change; like the preceding point (Cherubini et al., 2009; de Gorter and Tsur, 2009; Feng et al., 2008; Gnansounou et al., 2009; Menichette and Otto, 2008).

- conceptual mistake of LCA; (de Gorter and Tsur, 2009; Delucchi 2004; Feng et al., 2008).

In the following the LCA calculation methodology proposed by the directive has been compared with the main aspect emerged by the literature review just detailed. Where there is consistency there is an opportunity, while where the directive shows a lack of precision there is a threat.

\subsubsection{Opportunities}

- Within the directive the system boundaries is defined by the cultivation of biomass and by the use of biofuels in cars, this approach is in line with the well-to-wheel approach recommended in literature for LCAs of biofuels for transportation;

- the directive fixees which inputs must be considered in calculation of GHG emissions, while in the literature there is not an agreement about this choice; 
- the directive provides default values of GHG emissions, this data are representative of the typical European supply chains and, furthermore, they are conservative; in this way it should be an agreement in assessments at European level, while in literature the approach is not univocal;

- allocation method adopted in the directive is energy allocation; in the literature this approach does not appear as the best method, but is admitted that is almost exact; besides, energy allocation is more easy to perform;

- direct land use change is considered in the calculation methodology proposed by the directive, indeed it provides an equation to assess consequent GHG emissions or savings.

\subsubsection{Threats}

- the calculation methodology of the directive regards only a reference system relative to fossil fuels, while there is not a reference system for co-products and alternative uses of biomass;

- the functional unit fixed by the directive is mega joule of energy content, while it should be kilometre driven by cars in order to be consistent with the system boundaries;

- the directive does not consider other environmental impacts like acidification or eutrophication;

- the directive calculation method for GHG emission considers only energy efficiency of biomass processing, while does not consider the cogeneration processes;

- features of fossil fuels/biofuels mixtures are not considered in the directive;

- indirect land use change is not considered in the directive calculation method.

\section{Conclusions}

In this paper the directive 2009/28/EC has been analysed with the aim to find possible benefits and complications that his application could involve. Directive has been studied using the SWOT analysis conceptual structure, that identifies Strengths, Weaknesses in relation to the institutional framework and Opportunities and Threats in respect to literature review on LCA application to biofuel sector. The main result of the analysis allow to highlight the innovative feature of the directive and how its implementation could facilitate policy maker to reach the main goal of the European biofuel policy, promoting production and consumption of really sustainable biofuels. This scenario could stimulate the entry into the market of new ethical investors attracted by a r eal sustainable sector. However, some relevant aspects are not completely resolved like the relationship between biofuel development and fluctuation in commodity prices or the definition of the role played by rural area. On the other hand, from a technical point of view, some positive aspects with a certain importance are emerged too like, for example, the definition of default value for GHG emissions for all the EU, reaching an agreement in assessments at European level or the definition of the inputs to be considered in the calculation method. On the contrary the directive uses a functional unit that does not appear in line with the literature examine and, moreover, does not consider indirect land use change. Overall, considering that the directive is highly innovative, the presence of some weaknesses and threats can be considered normal. A deeper investigation would be useful to improve the efficiency of the EU biofuel policy.

\section{References}

[1] S. E. Koonin, Getting serious about biofuels, Science 311, 2006, p. 435

[2] L. Odling, Biofuels bandwagon hits a rut, Nature 446, 2007, p. 483 
[3] R. Righelato, D. V. Spracklen, Carbon mitigation by biofuels or by saving and restoring forests?, Science 317, 2007, p. 902

[4] J. Fargione, D. Tilman, Land clearing and the biofuel carbon debt, Science 319, 2008, pp. $1235-1237$

[5] J. M. Melillo, J. M. Reilly, D. W. Kicklighter, A. C. Gurgel, T. W. Cronin, S. Paltsev, B. S. Felzer, X. Wang, A. P. Sokolov, C. A. Schlosser, Indirect emissions from biofuels: how important?, Science 326, 2009, pp. 1397-1399

[6] D. Tilman, J. Hill, C. Lehman, Carbon-Negative biofuels from Low-Input High-Diversity Grassland Biomass, Science 314, 2006, pp. 1598-1600

[7] D. Kennedy, The biofuels conundrum, Science 316, 2007, p. 515

[8] G. P. Robertson, V. H. Dale, O. C. Doering, S. P. Hamburg, J. M. Melillo, M. M. Wander, W. J. Parton, P. R. Adler, J. N. Barney, R. M. Cruse, C. S. Duke, P. M. Fearnside, R. F. Follet, H. K. Gibbs, J. Goldenberg, D. J. Mladenoff, D. Ojima, M. W. Palmer, A. Sharpley, L. Wallace, K. C. Weathers, J. A. Wiens, W. W. Wilehlm, Sustainable biofuels redux, Science 322, 2008, pp. 49-50

[9] EBB (European Biodiesel Board), 2010. EBB Publishes Annual Biodiesel Production Statistics, Press Release, July.

[10] H. Feng, O. D. Rubin, B. A. Babcock, Greenhouse Gas Impact of Ethanol from Iowa Corn: Life Cycle Analysis versus System-Wide Accounting, American Agricultural Economics Association Annual Meeting, 2008, selected paper

[11]E. Gnansounou, A. Dauriat, J. Villegas, L. Panichelli, Life cycle assessment of biofuels: Energy and greenhouse gas balances, Bioresource Technology 100, 2009, pp. 4919-4930

[12] M. Quirin, M. Pehnt, G. A. Reinhardt, CO2 mitigation through Biofuels in the Transport Sector Status and Perspectives, IFEU- Institut fü $\rho$ Enepgie- und Umweltforschung Heidelberg Gmbh, 2004, Main report

[13]R. Rowe, Sustainable bioenergy and biofuels. Can life cycle analysis provide the answer?, Bioenergy news Issue 9, 2009, , pp. 2-4

[14] A. Singh, D. Pant, N. E. Korres, A. S. Nizami, S. Prasad, J. D. Murphy, Key issues in life cycle assessment of ethanol production from lignocellulosic biomass: Challenges and perspective, Bioresource Technology 101, 2009, pp. 5003- 5012

[15]F. Cherubini, N. D. Bird, A. Cowie, G. Jungmeier, B. Schlamadinger, S. WoessGallasch, Energy- and green house gas-based LCA of biofuel and bioenergy systems: key issues, ranges and recommendations, Resources, Conservation and Reciclling 53, 2009, pp. $434-447$

[16] D. Chiaramonti, L. Recchia, Is life cycle assessment (LCA) a suitable method for quantitative $\mathrm{CO}_{2}$ saving estimations? The impact of field input on the LCA results for a pure vegetable oil chain, Biomass and Bioenergy 34, 2010, pp. 787- 797

[17]E. D. Larson, A review of life-cycle analysis studies on liquid biofuel systems for the transport sector, Energy for Sustainable Development Vol. X No. 2, 2006, pp. 109-126

[18]E. Menichette, M. Otto, Energy Balance \& Greenhouse Gas Emission of Biofuels on a Life-Cylce Perspective, Proceednings of the Scientific Committee on Problems of the Environment (SCOPE) International Biofuels Project Rapid Assessment, 2008 
[19]M. A. Delucchi, Conceptual and methodological issues in lifecycle analyses of transportation fuels, U.S. Environmental Protection Agency Office of Transportation and Air Quality, 2004

[20]H. Croezen, B. Kampman, The impact of ethanol and ETBE blending on refinery operations and GHG- emissions, Energy Policy 37, 2009, pp. 5226- 5238

[21] L. Luo, E. van der Voet, G. Huppes, H. A Udo de Haes, Allocation issues in LCA methodology: a case study of corn stover-based fuel ethanol, International Journal of Life Cycle Assessment 14, 2009, pp. 529- 539

[22] M. Wang, H. Huo, S. Arora, Methods of dealing with co-products of biofuels in lifecycle analysis and consequent results within the U.S. context, Energy Policy (2010), doi:10.1016/j.enpol.2010.03.052.

[23]H. de Gorter, Y. Tsur, Towards a Genuine Sustainability Standard for Biofuel Production, Cornell University- Department of Applied Economics and Management New York, 2009, working paper. 